\title{
O sistema de conjunção em textos académicos: os mecanismos de sequenciamento e de explicação
}

The system of conjunction in academic texts: the mechanisms of sequencing and explanation

Orlando Vian Jr. Universidade Federal do Rio Grande do Norte Wellington Vieira Mendes Universidade Estadual do Rio Grande do Norte

Text is the process of meaning; and a text is the product of that process.

(HALLIDAY, 2002 [1982], p. 221)

Resumo: Dentre os seis sistemas discursivos propostos por Martin e Rose (2007 [2003]), o sistema de conjunção possibilita analisar as relações entre os processos de um texto com base em quatro tipos gerais de conjunções: adição, comparação, tempo e consequência. A partir de um recorte do corpus dos textos que compõem o SAL - Systemics Across Languages, nosso objetivo neste texto é observar como se caracterizam as relações conjuntivas em textos acadêmicos, com foco nas ocorrências léxico-gramaticais de sequenciamento e de explicação, como forma de explorar o texto acadêmico em quatro realizações distintas: um artigo de graduação, um trabalho de conclusão de curso de graduação, uma dissertação de mestrado e uma tese de doutorado. 0 objetivo primordial é explorar como os mecanismos estão organizados nos quatro níveis acadêmicos e o que revelam sobre a produção textual, fornecendo subsídios para outros estudos sobre textos e gêneros acadêmicos que, por sua vez, podem embasar propostas de letramento acadêmico, principalmente no que diz respeito à formação do pesquisador e sua produção textual e o ensino da produção escrita. 
Palavras-chave: análise de discurso, sistema discursivo de conjunção, sequenciamento, explicação, texto acadêmico.

Abstract: Among the six discursive systems proposed by Martin and Rose (2007 [2003]), the system of Conjunction makes it possible to analyze the relationships within the processes of a text based on the four general types of conjunction: addition, comparison, time and consequence. Using samples from texts in the Systemics Across Languages -

Orlando VianJr.

Wellington

Vieira Mendes

164

SAL corpus, our objective in this study is to observe how the conjunctive relationships are characterized in academic texts, focusing on the lexico-grammatical instances of sequencing and explanation, as a way of exploring academic texts in four distinct modes: undergraduate article, concluding undergraduate work, Master's thesis, and Doctoral dissertation. The main objective is to explore how the mechanisms are organized at the four academic levels, and what these mechanisms reveal about text production, providing support for other studies on academic genres and texts, which can then be used at the basis for academic literacy proposals, primarily aimed at researchers in training and their text production, as well as teaching writing.

Key words: discourse analysis, conjunction system, sequencing, explanation, academic texts.

\section{Texto e discurso}

Compreender o modo como se estrutura o texto acadêmico permite que se desvelem não apenas as características léxico-gramaticais realizadas nos textos, mas também o modo como os sentidos são construídos no estrato semântico-discursivo, bem como as relações dos textos com os contextos em que são produzidos. Isso possibilita compreender, por conseguinte, os textos como produtos de processos de construção de sentidos, como preceituado por Halliday e ilustrado na epígrafe.

Esse entendimento aponta para a perspectiva sistêmico-funcional de língua(gem) proposta por Halliday (1978; 1985), isto é, uma visão metafuncional e estratificada, em que os sentidos interpessoais, ideacionais e textuais ocorrem simultaneamente para a construção dos significados no texto e em que, ao mesmo tempo, as escolhas em um estrato projetam construções no estrato seguinte. As escolhas no estrato grafofonológico são a realização das escolhas do estrato léxico-gramatical. Estas, por seu turno, estão realizando escolhas no estrato semântico-discursivo, sendo que tais escolhas ocorrem em contextos de cultura e de situações distintos. 
O desvelar de tais sentidos permite ainda que se compreendam as práticas de letramento acadêmico nos contextos em que ocorrem e, a partir daí, possam ser encaminhadas questões de ensino e de planejamento de cursos, de forma a deflagrar processos em que a produção da escrita acadêmica seja concebida como prática social e parte de um processo interativo entre texto-produtor-leitor/ouvinte, em que elementos sociais e linguísticos estejam interligados para a construção dos significados.

Analisar o discurso pelo prisma da Linguística Sistêmico-Funcional (LSF, doravante), significa tratá-lo como mais do que palavras em orações, mas além das orações, nos recursos semânticos que se desencadeiam nas relações entre as orações ao passo que o texto se desenvolve (MARTIN; ROSE, 2007 [2003, p. 1).

O sistema de

conjunção

em textos

acadêmicos:

osmecanismos de sequenciamento e de explicação

Essa abordagem significa, ainda, tratar o discurso como mais do que uma manifestação incidental da atividade social, mas para além disso, ou seja, como atividade social construída em textos em relação aos papéis constitutivos dos sentidos na vida social, de acordo com os mesmos autores.

Para tanto, é necessário que se considere a intrínseca relação oração-texto-cultura, uma vez que os textos são produzidos de modo interativo entre os interactantes nas relações sociais, e as orações que constroem para tecer seus textos estão relacionadas aos sentidos nas interações sociais e devem ser considerados como desdobramentos destas; por conseguinte, são a manifestação da cultura em que tais interactantes estão imersos.

Consideraremos, desse modo, a visão de texto na esteira do pensamento desses autores, de uma perspectiva de "língua no contexto social", cujos desenvolvimentos remontam à própria evolução da perspectiva sistêmico-funcional concebida por Halliday, como assevera Martin (2009, p.154), indo desde a preocupação de Firth com a função do sentido no contexto, passando pelas propostas de Halliday da função do discurso em sua gramática, bem como os estudos sobre tema/rema, culminando com sua proposta do sentido além da oração, a partir dos estudos de coesão contidos em Halliday e Hasan (1976). Portanto, podemos estabelecer como ponto fundacional dos estudos em discurso a noção de texto que, como afirmam, pode ser mais adequadamente referido como uma unidade semântica, isto é, uma unidade não de forma, mas de sentido (HALLIDAY; HASAN, 1976, p. 2). 
O estudo desses autores propiciou subsídios para futuras am-

pliações a aplicações, que estimularam pesquisas sobre registros não só no âmbito da Escola de Sydney, mas também em outros centros acadêmicos ao redor do mundo, culminando com os estudos e o desenvolvimento da análise de gêneros.

Restringindo nosso enfoque aos estudos em análise do discurso, abordaremos, neste texto, a proposta analítica concebida por Martin e Orlando VianJr. $\quad$ Rose (2007 [2003]), constituída de seis sistemas discursivos explicitados no item subsequente. Nosso foco recairá sobre o sistema de conjunção e, Wellington com base nele, o texto inicia pela sua apresentação e como este se conVieira Mendes figura, com foco nos mecanismos de sequenciamento e de explicação. Apresentamos, na sequência, o corpus utilizado para a pesquisa, bem como a metodologia de análise dos dados para, logo depois, analisarmos os dados e discutirmos os resultados obtidos, seguidos de nossas considerações sobre os mecanismos observados.

\section{Os sistemas discursivos e o sistema de conjunção}

Tendo o trabalho de Halliday e Hasan (1976) como ponto de partida, muitos outros se derivaram e ofereceram ampliações dos estudos sobre texto, gramática, registro, gênero e discurso. Para o escopo deste texto, focaremos esse estudo de Halliday e Hasan (1976) e seu trabalho sobre coesão, posteriormente ampliado em Martin (1992) e, mais tarde, com desenvolvimentos em Martin e Rose (2007 [2003]). O inventário de recursos coesivos proposto por Halliday e Hasan (1976) está organizado em quatro tipos de mecanismos: referência, elipse, substituição, conjunção e coesão lexical. Com base nele, o trabalho de Martin (1992) oferece uma ampliação, inspirada principalmente na semântica de orientação textual dos estratificacionalistas de Hartford, principalmente Gleason e Gutwinski, com os quais Martin (2009, p. 156) informa ter estudado em Toronto.

Na proposta contida em Martin (1992), temos a coesão reformulada como um conjunto de sistemas discursivos em um nível mais abstrato do que o léxico-gramatical e que compreende quatro sistemas discursivos: identificação, negociação, conjunção e ideação.

O que se tem com essa reformulação é um estrato semântico do texto de recursos dedicados à análise das relações coesivas como estrutura discursiva (MARTIN, 2009, p.157), de modo que os quatro sistemas discursivos podem ser alinhados ao estrato léxico-gramatical do seguinte modo: 


\begin{tabular}{|c|c|}
\hline Sistema discursivo & Significado relacionado \\
\hline Identificação & Textual \\
\hline Negociação & Interpessoal \\
\hline Conjunção & Lógico \\
\hline Ideação & Experiencial \\
\hline
\end{tabular}

\section{Quadro 1 - Significados dos sistemas discursivos}

(com base em MARTIN, 1992)

Posteriormente esses quatro sistemas foram ampliados por Martin e Rose (2007 [2003]), aos quais dois outros sistemas foram adicionados: periodicidade e avaliatividade.

Se considerarmos as funções sociais para as quais usamos a língua (deflagrar nossas relações sociais, representar nossas experiên-

O sistema de conjunção em textos acadêmicos: osmecanismos de sequenciamento e de explicação cias, organizarmos tais relações e representá-las em textos), temos as metafunções da língua na atividade social (Martin; Rose, 2007[2003], p. 7). Podemos esquematizar tais relações, com seus respectivos sentidos, conforme Quadro 2:

\begin{tabular}{|c|c|c|c|}
\hline \multicolumn{2}{|c|}{ Sistema discursivo } & \multicolumn{2}{|l|}{ Metafunção } \\
\hline Identificação & Rastrear pessoas e coisas & \multirow{2}{*}{ Textual } & \multirow{2}{*}{$\begin{array}{l}\text { Organizar os } \\
\text { textos }\end{array}$} \\
\hline Periodicidade & Fluxo de informação & & \\
\hline Negociação & Promover trocas & \multirow{2}{*}{ Interpessoal } & \multirow{2}{*}{$\begin{array}{l}\text { Deflagrar } \\
\text { relações sociais }\end{array}$} \\
\hline Avaliatividade & Negociar atitudes & & \\
\hline Conjunção & Conectar eventos & \multirow{2}{*}{ Ideacional } & \multirow{2}{*}{$\begin{array}{l}\text { Representar a } \\
\text { experiência }\end{array}$} \\
\hline Ideação & Representar a experiência & & \\
\hline
\end{tabular}

\section{Quadro 2 - Relação sistemas discursivos/metafunções}

(com base em MARTIN; ROSE, 2007[2003])

Como estamos interessados nos mecanismos de conjunção, apresentaremos uma descrição sucinta dos mecanismos atinentes a esse sistema discursivo, que está relacionado ao modo como os eventos estão conectados, contribuindo para o desenvolvimento do fluxo de informações no texto. Por essa razão, o sistema apresenta interfaces com dois outros: uma com o sistema de ideação, que constrói a experiência como uma sequência de atividades logicamente organizadas, e outra com o sistema de periodicidade, que apresenta o discurso como ondas de informação logicamente organizadas (MARTIN; ROSE, 2007 [2003], p. 116). 
É importante sinalizar, contudo, que o sistema de conjunção proposto pelos autores concebe a conjunção como um conjunto de significados que, por um lado organizam as sequências de atividade e, por outro, $o$ texto. Os autores sinalizam que este modelo difere, portanto, dos modelos como os de Halliday e Hasan (1976) e o de Halliday e Matthiessen (2004), que tratam as conjunções como recursos gramaticais que ligam orações.

Orlando VianJr.

Wellington

Vieira Mendes

168

\subsection{0 sistema de conjunção}

De modo sintético, podemos afirmar que o sistema de conjunção enfoca as interconexões entre os processos, por meio de mecanismos de adição, comparação, sequenciamento e explicação. Tais mecanismos, assim, podem ser considerados significados lógicos que relacionam atividades e mensagens sequenciadamente.

Na concepção de Martin e Rose (2007 [2003]), as conjunções são classificadas de acordo com aquelas que relacionam atividades e aquelas que organizam o texto. As conjunções externas, segundo os autores, são aquelas que relacionam atividades, uma vez que constroem um campo para além do texto. Já as conjunções internas estabelecem relações dentro do próprio texto. A título de ilustração, apresentamos no Quadro 3 as opções básicas de conjunções externas:

\begin{tabular}{|c|c|c|}
\hline \multirow[t]{2}{*}{ adição } & adição & e, além disso, em adição \\
\hline & alternância & ou, se não - então, alternativamente \\
\hline \multirow[t]{2}{*}{ comparação } & igualdade & como, como se, similarmente \\
\hline & adversidade & mas, ao passo que, por outro lado \\
\hline \multirow[t]{2}{*}{ tempo } & sucessão & $\begin{array}{l}\text { então, depois, subsequentemente, antes, } \\
\text { previamente }\end{array}$ \\
\hline & simultaneidade & enquanto, enquanto isso, ao mesmo tempo \\
\hline \multirow[t]{4}{*}{ consequência } & causa & assim, porque, desde que, logo \\
\hline & meio & por, assim, por meio \\
\hline & finalidade & para, a fim de, por meio de \\
\hline & condição & se, desde que; a menos que \\
\hline
\end{tabular}

Quadro 3: Opções básicas de conjunções externas

(traduzido/adaptado de MARTIN; ROSE, 2007 [2003], p. 122)

Os tipos de conjunções externas incluem os mesmos tipos de conjunção interna, pois muitos itens que expressam relações internas expressam também relações externas; o diferencial está nos sentidos 
construídos nos textos. Como abordaremos apenas os mecanismos entre orações nos textos analisados, não discutiremos as conjunções externas. Remetemos o leitor do trabalho de Martin e Rose (2007 [2003]), p. 133)

Além das conjunções externas e internas, existe ainda um conjunto de conectores diferente das conjunções, denominado de continuativos, cujas opções básicas estão ilustradas no Quadro 4:

O sistema de

conjunção

em textos

acadêmicos:

osmecanismosde sequenciamento e de explicação

Em relação ao modo como as conjunções são analisadas em um texto, Martin e Rose (2007 [2003]) propõem o uso de diagramas com elementos diferenciados para análise da organização lógica do discurso, por meio do uso de códigos para os diferentes tipos de conjunções (conforme Quadro 5) e um mecanismo para explicitação das conexões entre as mensagens do texto, feito por meio do uso de setas, indicando tanto as conjunções internas quanto externas. Esse mecanismo, segundo Martin e Rose (2007 [2003], p.146), permite ilustrar o modo como um texto desenvolve-se logicamente, pela conjunção entre figuras, fases e os estágios do texto. Sinalizamos, no entanto, que não usaremos estes mecanismos pelo fato de estarmos utilizando um corpus maior do que os textos utilizados pelos autores e com textos que pertencem a diferentes gêneros acadêmicos.

Com base nos tipos de conjunções externas e internas apresentadas, nos continuativos e nos elementos propostos para análise, apresentamos a seguir a análise dos textos que compõem o corpus de estudo.

\subsection{0 corpus e as opções da pesquisa}

Nas proposições indicadas por Martin e Rose (2007 [2003], p. 143-148), a metodologia empregada para a análise do sistema de conjunção consiste 
na classificação dos tipos de conjunção e nos seus significados, a partir da indicação de setas, com uso das abreviações sugeridas no Quadro 5:

\begin{tabular}{c|llll|}
\cline { 2 - 3 } & Adição & aditiva & adt \\
& Comparação & $\begin{array}{l}\text { alternativa } \\
\text { alt }\end{array}$ & igu \\
& igualdade & adv \\
Orlando VianJr. & Tempo & adversidade & suc \\
& sucessão & sim \\
Wellington & Consequência & simultaneidade & cau \\
& & causa & mei \\
& & meio & fin \\
& & finalidade & con \\
\hline
\end{tabular}

Quadro 5: Abreviações para os tipos de conjunções

(traduzido de MARTIN; ROSE, 2007 [2003], p. 144)

Esses mecanismos apontam para os referentes presentes nos discursos (realização fórica), estabelecendo os sentidos pretendidos no texto por meio das configurações conjuntivas.

Neste trabalho, propomo-nos analisar as principais ocorrências de conjunções presentes em quatro gêneros de textos acadêmicos, quais sejam: um artigo de graduação (ART), um trabalho de conclusão de curso (TCC) de graduação, uma dissertação de mestrado (DIS) e uma tese de doutorado (TES) - um recorte do corpus dos textos que compõem o SAL (Systemics Across Languages). Esses quatro textos selecionados para a composição de um corpus mínimo são da área da Linguística e versam sobre temáticas variadas.

Na Tabela 1, apresentamos o corpus (em termos estatísticos), descrito a partir da ferramenta WordList (SCOTT, 2012):

\begin{tabular}{l|l|l|l|l}
\hline Gênero & $\begin{array}{l}\text { Número de } \\
\text { palavras }\end{array}$ & Tokens & Types & $\begin{array}{l}\text { Razãotype/token } \\
\text { (densidade) }\end{array}$ \\
\hline ART & 3.877 & 3.798 & 1.124 & 29,59 \\
\hline TCC & 17.268 & 16.908 & 3.241 & 19,17 \\
\hline DIS & 26.000 & 25.075 & 3.568 & 14,23 \\
\hline TES & 94.318 & 91.498 & 7.465 & 8,16 \\
\hline total/média & $\mathbf{1 4 1 . 4 6 3}$ & $\mathbf{1 3 7 . 2 7 9}$ & $\mathbf{1 0 . 0 6 2}$ & $\mathbf{7 , 3 3}$ \\
\hline
\end{tabular}

Tabela 1 - Composição do corpus da pesquisa

Fonte: os autores 
A disposição da Tabela 1 é apenas um indicador de como os números apresentados configuram uma espécie de gradação entre os gêneros aqui estudados, tanto no que se refere à quantidade de palavras, como no modo como essas realizações léxico-gramaticais se repetem ao longo do texto. A densidade, por exemplo, é bem mais expressiva nos dois primeiros gêneros em comparação com os dois últimos - um indício de como a repetição se apresenta mais recorrente entre os gêneros cujos autores são ainda menos experientes na produção acadêmica.

A partir dos dados estatísticos, procedemos ao levantamento das ocorrências de conjunções, por gênero, tendo como base a ferramenta Concord (SCOTT, 2012). Tendo em conta o volume textual, bem como nosso interesse de indicar apenas algumas aproximações do sistema de conjunção com textos em língua portuguesa, detivemo-nos basicamente no padrão

O sistema de conjunção em textos acadêmicos: osmecanismosde sequenciamento e de explicação de recorrência mais/menos saliente nos dados. Assim, selecionamos, das quatro relações lógico-semânticas (adição, comparação, tempo e consequência), as ocorrências realizadas conforme indicadas no Quadro 6:

\begin{tabular}{|llll|}
\hline $\begin{array}{l}\text { Relação } \\
\text { lógica }\end{array}$ & Sentido & $\begin{array}{l}\text { Ocorrências selecionadas/ } \\
\text { realização pesquisada no corpus }\end{array}$ & $\begin{array}{l}\text { Abreviação } \\
\text { utilizada }\end{array}$ \\
\hline adição & Aditiva & além disso, e também, mas também & adt \\
& Alternativa & ou & alt \\
comparação & Igualdade & como, como se & igu \\
& Adversidade & ao passo que, por outro lado & adv \\
tempo & Sucessão & depois, antes & suc \\
& Simultanei- & enquanto isso, ao mesmo tempo & sim \\
& dade & tanto que & cau \\
consequência & Causa & por meio & mei \\
& Meio & a fim de & fin \\
& Finalidade & con \\
& Condicional & desde que & \\
\end{tabular}

Quadro 6 - Realizações léxico-gramaticais de conjunções pesquisadas em português

Fonte: Os autores

O leitor deve ter notado que há uma diferença entre as realizações apontadas no Quadro 6 e no que fora traduzido de Martin e Rose (2007 [2003], p. 122). Essas diferenças consistem basicamente no fato de que, em língua portuguesa, podemos não ter as mesmas relações lógico- 
Orlando VianJr.

Wellington

Vieira Mendes semânticas que ocorrem em inglês a partir das conjunções internas/ externas que os teóricos indicam. Evidentemente, há estudos no Brasil (p.ex. NEVES, 2011 [1999] e CASTILHO, 2010) que abordam as relações conjuntivas em diferentes perspectivas, com paradigmas muito próximos, e que em muito se assemelham ao que está indicado. 0 que estamos propondo, igualmente, é o estudo dessas relações a partir das bases teóricas da LSF, cujos estudos já estão bastante aplicados e difundidos em língua inglesa, e ainda incipientes no português.

Feitas essas observações de caráter mais operacional, passamos às análises das ocorrências identificadas no corpus, conforme estabelecido no Quadro 6 imediatamente anterior.

\section{0 sistema de conjunção nos gêneros acadêmicos}

Nesta seção, apresentamos a análise das relações lógico-semânticas propostas por Martin e Rose (2007 [2003]), em duas partes principais: na primeira, discutimos as relações expressas pelas conjunções aditivas e comparativas; na segunda parte, apresentamos as realizações das conjunções de tempo e consequência. Essa disposição, ou agrupamento em quatro tipos de relação lógico-semânticas, já é em si mesma uma diferença das propostas que, até então, temos encontrado nos estudos difundidos no Brasil.

Antes, porém, apresentamos na Tabela 2 o percentual de ocorrências das conjunções selecionadas, por gênero em que ocorrem. Em termos absolutos, são 1.348 casos de conjunções, sendo a maior parte delas de relações aditivas, com uso de "ou". 


\begin{tabular}{|c|c|c|c|c|c|c|}
\hline \multirow{2}{*}{\begin{tabular}{|l} 
Relação \\
lógica
\end{tabular}} & \multirow{2}{*}{ Sentido } & \multirow{2}{*}{$\begin{array}{l}\text { Realização no } \\
\text { corpus }\end{array}$} & \multicolumn{4}{|c|}{ \% de ocorrências nos gêneros } \\
\hline & & & ART & TCC & DIS & TES \\
\hline \multirow{4}{*}{ adição } & \multirow{3}{*}{ aditiva } & além disso & - & 42 & - & 58 \\
\hline & & e também & 4 & 37 & 7 & 52 \\
\hline & & mas também & - & 10 & 3 & 87 \\
\hline & alternativa & ou & 1 & 8 & 14 & 77 \\
\hline \multirow{3}{*}{$\begin{array}{l}\text { compa- } \\
\text { ração }\end{array}$} & igualdade & comose & - & 5 & 12 & 83 \\
\hline & \multirow{2}{*}{ adversidade } & ao passo que & - & - & - & 100 \\
\hline & & por outro lado & 5 & - & 27 & 68 \\
\hline \multirow{4}{*}{ Tempo } & \multirow{2}{*}{ sucessão } & depois & - & 17 & 10 & 73 \\
\hline & & antes & - & 23 & 12 & 65 \\
\hline & \multirow{2}{*}{$\begin{array}{l}\text { simultanei- } \\
\text { dade }\end{array}$} & enquanto isso & - & 100 & - & 0 \\
\hline & & ao mesmo tempo & 2 & 5 & 59 & 34 \\
\hline \multirow{4}{*}{$\begin{array}{l}\text { conse- } \\
\text { quência }\end{array}$} & causa & tanto que & - & - & - & 100 \\
\hline & meio & por meio & - & 53 & 18 & 29 \\
\hline & finalidade & a fim de & - & 40 & - & 60 \\
\hline & condicional & desde que & - & - & - & 100 \\
\hline
\end{tabular}

O sistema de conjunção em textos acadêmicos: osmecanismosde sequenciamento e de explicação

Tabela 2 - Percentual de ocorrências de conjunções do corpus da pesquisa Fonte: Os autores

Embora não seja nosso objetivo proceder a uma análise tipicamente quantitativa, os dados recorrentes configuram importantes meios a partir dos quais o pesquisador pode iniciar seu percurso analítico. A simples observação da Tabela 2 aponta para dados que apresentam saliência. Por exemplo, chamam a atenção as ocorrências, apenas no gênero tese, das conjunções "ao passo que", "tanto que" e "desde que". o mesmo se pode dizer de "enquanto isso", apenas no TCC. Essas ocorrências mais isoladas não significam necessariamente que tais construções se processem apenas no gênero aqui disposto. Como advertimos em outras partes deste estudo, temos apenas um exemplar de cada gênero, a título de amostragem mínima, não sendo possível, portanto, fazer afirmações definitivas acerca do fenômeno analisado.

Por outro lado, esses casos podem indicar predileção dos autores por construções que remetam a uma maior complexidade do ponto de vista da estruturação - como parece ser o caso das que se sobressaíram na tese.

Outro dado que salta aos olhos é o número mais reduzido de conjunções no gênero artigo, não havendo nenhuma ocorrência de relação lógico-semântica de consequência, por exemplo. Na verdade, as conjun- 
Orlando VianJr.

Wellington

Vieira Mendes

ções estão concentradas prioritariamente entre adição e comparação. Esse dado reforça o que já havíamos apresentado na Tabela 1, acerca da densidade dos gêneros analisados, ou seja, o gênero artigo, por ser mais compacto e, nesse caso específico, por ter sido produzido por aluno de graduação, apresenta uma maior recorrência aos textos-fonte e com menor (re)análise do conteúdo apresentado nestes mesmos textos. Esse tipo de ocorrência seria mais bem definido e caracterizado se outros artigos de alunos de graduação fossem comparados entre si e estes comparados a artigos produzidos por pesquisadores experientes, para que pudéssemos tecer considerações mais definitivas sobre tais ocorrências em nível iniciante e proficiente. Nosso foco neste texto, no entanto, é o de estabelecer os primeiros diálogos com a teoria de Martin e Rose e 174 observarmos ocorrências em língua portuguesa para que aspectos tipológicos da língua sejam contrastados com os mecanismos observados em inglês e o sistema seja utilizado em português para que o fenômeno seja compreendido de modo mais específico.

Na sequência, apresentamos a discussão desses dados, tendo como procedimento de análise a interpretação/compreensão das relações construídas pelo sistema de conjunção nos textos selecionados.

\subsection{As relações de adição e de comparação}

As relações lógico-semânticas indicadas neste estudo se prestam, entre outros papéis, a sequenciar e contribuir para as explicações pretendidas pelos autores de textos, especialmente no caso dos gêneros acadêmicos. Para ir além, tais relações estabelecem os sentidos nos textos e ao mesmo tempo contribuem para a sua caracterização enquanto gêneros ou mesmo para atribuir-lhes funções específicas, que podem ser reconhecidas nos contextos em que circulam.

Logo, mais que pura e simplesmente funcionar como uma realização lexical na superfície do texto para garantia de coesão, as relações lógicas construídas no texto situam e constroem o discurso porque configuram relações/atividades dentro do próprio texto e para além dele.

Assim, as relações de adição e de comparação se prestam ao papel de acrescentar sequência(s) a um primeiro segmento, podendo estabelecer sentidos de correlações, contraste ou adversidade, ou de alternância. Essas relações podem ser facilmente identificadas em textos com predominância de narração, como exemplificam Martin e Rose (2007 [2003], p. 144-5). 
Identificamos nos gêneros TCC e tese o maior número de ocorrências dessas relações. No primeiro, o uso da conjunção "além disso" é bastante recorrente para fazer enumerações; por exemplo., o escrevente indica, sob a forma de sequência, os elementos dispostos em seu quadro de análise. Os empregos mais presentes remetem sempre a um papel menos marcado da conjunção, ou seja, quase sempre há a relação entre segmentos de estatuto léxico-gramatical semelhante:

1) [...] podemos visualizar as barras de navegação (frame 5) e os posts (frame 6) que vem acompanhado do dia da semana, data e ano. Além disso, encontramos a descrição numérica do total de visitantes (frame 7) e o calendário (frame 8) e nas imagens a seguir [...] $\left(\right.$ adt-375-TCC) ${ }^{1}$

O sistema de conjunção em textos acadêmicos: osmecanismos de sequenciamento e de explicação

2) [...] teóricos nos quais pesquisei trataram dos problemas e a partir disto, vou inserindo minha visão sobre o assunto. Além disso, procuro apresentar algumas soluções para a problemática.[...] (adt1886-TES)

3) [...] por apresentar determinadas ambiguidades, não comprimento de objetivos, pode gerar confusões no leitor, além disso, por apresentar dados de análise muito extensos pode desmotivá-lo a ler [...] (adt-2795-TES)

O uso mais marcado de "além disso" é como conjunção interna, estabelecendo relação entre as partes do texto, ou como já dissemos, prestando-se a sequenciador. Na maior parte das ocorrências, verificamos que essa conjunção é empregada no início do período, estando o produtor textual apontando um novo tópico, a partir do que fora dito antes, como atividade possível e sucessora. Em (3), entretanto, a relação estabelecida pelo segmento, introduzido pela conjunção, aponta mais para um caráter de hierarquia das informações do que para sequência.

No que diz respeito ao emprego de "e também", presente em todos os textos analisados, verificamos uma realização diferente daquela

1. As amostras do corpus foram identificadas neste texto pelo tipo de relação lógica (cf. abreviaturas no Quadro 6), bem como pelo número da sentença, indicado pela listagem elaborada pelo WordSmith Tools (SCOTT, 2010), e, por último, pela abreviatura dos textos (ART, TCC, DIS, TES). 
presente no item analisado anteriormente. Nesses casos, "e também" apresenta-se com maior recorrência na relação entre estruturas menores da sentença (4), chamando atenção para elementos novos introduzidos na sequência (5) e, em menor número de ocorrências, fazendo a relação de adição entre partes de estatuto léxico-gramatical correspondentes, como que num paralelismo (6):

Orlando VianJr.

Wellington Vieira Mendes 176
4) Em outras circunstâncias e esferas sociais, a escrita precisa ser vista cumprindo papeis específicos e também intelectualizados, que definirão necessidades imediatas de seu uso. (adt-1285-TES)

5) [...] escolha de como apresentará uma situação de escrita, como tratará o texto e estabelecerá relações com o gênero - e também para o aluno - quais as ações a serem desempenhadas pelo gênero, quais elementos deverão ter sua recorrência [...] (adt-1057-TES)

6) Por isso, o discurso é tomado como o ponto de partida para a gramática e também como ponto de chegada. (adt-41-ART)

De forma semelhante, as sucessões de "mas também" incorporam ao discurso o sentido de cumulação paralela (7), numa razão de correspondência biunívoca; ou um evento/atividade que sucede outro como sendo condição inopinada e que remete a atenção do leitor para o que vem a ser dito depois da conjunção. Nesses casos, aponta, inclusive, para uma gradação argumentativa na qual o segmento introduzido pela conjunção passa a ter a característica de argumento último (8):

7) [...] se configurando nos últimos tempos como um ambiente de pesquisas não apenas externas, ou seja, fora do universo acadêmico, mas também internas, o espaço acadêmico como produtor de discursos específicos, com o intuito de averiguação do alcance [...] (adt-52-DIS)

8) Em função desse dinamismo, o texto acadêmico é concebido como ação (BRONCKART, 1999), mas também como resultado de operações frequentes e contínuas de transformações do saber científico. (adt-663-TES) 
Como último exemplo de relação lógico-semântica de adição, descrevemos as ocorrências da conjunção "ou", cujo sentido principal é de alternativa/alternância. $O$ uso dessa conjunção é comum aos quatro textos analisados e realizam, basicamente, o sentido de alternância (9), ou seja, sucessão de atividades que podem ocorrer reciprocamente, sob a forma de revezamento. É menos recorrente a realização de alternativa, em que são configurados eventos/atividades exclusivas (10).

9) [...] os textos produzidos como condição para que os alunos participassem de eventos científicos (Exemplos 07 e 09) ou que tiveram uma orientação mais sistemática do professor (Exemplos 06 e 08) revelam que eles estiveram [...] (alt-2916-TES)

O sistema de

conjunção

em textos

acadêmicos:

osmecanismos de

sequenciamento

e de explicação

10) [...] com um efeito anestésico sobre o senso de plausibilidade do professor. Senso de plausibilidade é o sentido (ou teoria, ou, num estado mais latente, uma intuição pedagógica) de como a aprendizagem acontece, e de como o ensino a causa [...] (alt-222-TCC)

Devemos registrar ainda que a conjunção "ou", quando se realiza como nessa última amostra, estabelece quase sempre uma separação entre os termos coordenados, de modo exclusivo, ou seja, mobiliza sentido de alternativa, já que o evento ou atividade exclui mutuamente o outro. Outras ocorrências também comuns nos textos deste corpus correspondem à realização de "ou não", cuja alternância tem relação com a polaridade das sentenças (positivas/negativas), que se manifesta nos textos em muitos casos para modalizar a linguagem científica, como podemos verificar em (11):

11) [...] o aluno age de acordo com algumas exigências que lhe são impostas, considerando se a ação corresponderá a uma avaliação ou não. (alt-222-TCC)

12) A produção do artigo estimula a capacidade crítica dos alunos, ou seja, a capacidade de questionar. (alt-2668-TES)

13) [...] o estabelecimento de estratégias de produção textual, as crenças de ensino refratam-se, inegavelmente, nas de aprendi- 
zagem, ou seja, aquilo que os professores demonstram, acreditam e fazem são, pouco a pouco, absorvidos pelos alunos. (alt-2906-TES)

Há também os casos frequentes em que essa conjunção é empregada como recurso para construção de metáfrase, quando a não transposição do já dito como forma de ênfase, emenda (12), ou simplesmente como recurso de ampliação de um referente anterior à conjunção, como Orlando VianJr. $\quad$ se pode verificar em (13). Casos de correção metalinguística não foram observados no corpus, possivelmente porque, como os textos aqui anaWellington lisados circulam na academia, o uso desse recurso pode não cumprir os Vieira Mendes mesmos papéis que comumente efetuam em gêneros menos formais.

Já nas realizações lógico-semânticas de comparação, observamos 178 que as conjunções com significado de igualdade e de adversidade ocorrem nos quatro textos, a não ser pelo caso de "ao passo que", cujo padrão de recorrência foi discutido no início desta seção. A comparação de igualdade realizada pela conjunção "como se" só não ocorre no artigo de graduação. Nos demais gêneros, o seu uso manifesta relação semântica circunstancial de modo, especialmente nos processos cujo modo não é realis. Nesses casos, a marcação típica de comparação mobiliza o sentido de hipótese, conforme se pode ver na amostra (14):

14) [...] quatro ou seja, $31 \%$ dos textos analisados não apresentaram nenhum indício de contribuições para com a ciência, como se $a$ pesquisa não tivesse nenhuma relação com algum estudo feito sobre a mesma temática. (igu-607-DIS)

Merece registro o fato de que não é esse o modelo de maior frequência no corpus. Na verdade, a configuração que mais ocorre é tipicamente circunstancial, indicando a maneira como os processos/atividades da sentença introduzida pela conjunção acontecem. $O$ entendimento dessa realização ideacional se deve basicamente ao modo como operam os papéis do sistema de transitividade (processos, participantes e circunstâncias), em que as circunstâncias podem construir significados não apenas adverbiais (como preceitua a tradição), mas também contribuem para a modalização e argumentação textuais (MENDES, 2010).

As conjunções de adversidade realizam, em todas as amostras coletadas, o significado de compensação argumental. Do total de 22 ocorrências, 14 se efetuam na léxico-gramática introduzindo a senten- 
ça (15); as demais ora recuperam o referente do período anterior, pela indicação de participante explícito (16), ora reforçam o caráter de adversidade pelo reforço de "mas" (17).

15) [...] conversas oriundas de favores como o empréstimo de uma caneta, um isqueiro, um papel, por exemplo. Por outro lado, os gêneros secundários são mais complexos por estarem vinculados à manifestações linguísticas [...] (adv-104-DIS)

O sistema de conjunção em textos acadêmicos: osmecanismosde sequenciamento e de explicação cativo ("possibilita"). Essa evidência constataria, por outro lado, a ausência de uma revisão linguística criteriosa ao final do texto ou o desconhecimento de como [...] (adv-2835-TES)

17) [...] conceitua/define o artigo acaba por orientar, de forma muito positiva, as escolhas das estratégias. Mas, por outro lado, subtrai as possibilidades de o artigo poder assumir novas dimensões, como, por exemplo [...] (adv-2100-TES)

As amostras analisadas, portanto, reforçam as possibilidades de sentidos que podem adquirir os enunciados, tendo em conta não apenas a relação que as conjunções comparativas condicionam, mas, principalmente, os efeitos pretendidos por seus autores quando dispõem, nas diferentes construções léxico-gramaticais, esses valores semânticos. Mais do que isso, o uso da conjunção comparativa "por outro lado" evidencia a propriedade dialógica do texto, à medida que mobiliza argumentos que podem indicar oposição, complementação ou mesmo compensação.

Na seção que segue, analisamos as relações lógico-semânticas de tempo e de modo, a partir das amostram presentes no corpus - a exemplo do que fizemos até então.

\subsection{As relações de tempo e de consequência}

As relações lógico-semânticas de tempo e de consequência também se incluem no inventário léxico-gramatical com o fim de vincular as sentenças no discurso, podendo, a exemplo do que foi dito das relações de adição e comparação, estabelecer sentidos diversos, para além do que prevê, por exemplo, a tradição gramatical ainda vigente no ensino de língua materna. 
As conjunções de tempo, com significado de sucessão e simultaneidade, ocorrem em praticamente todos os textos que constituem o corpus de análise. "Antes" e "depois" são bastante recorrentes, com maior frequência no gênero tese, indicando relações entre eventos/ atividades que se sequenciam no desenvolvimento do discurso. As relações lógicas de tempo podem ser expressas por uma grande variedade de formas, especialmente por circunstâncias que, associadas

Orlando VianJr.

Wellington Vieira Mendes a processos e participantes podem indicar duração ou localização temporal. No caso específico deste estudo, a configuração do sistema de conjunção é apontada como sendo responsável pelo estabelecimento de significados de sucessão (quando um evento sequencia outro) e simultaneidade (quando eventos/atividades podem ocorrer concomitantemente).

É importante registrar que as conjunções "antes" e "depois" são analisadas pelo sentido que mobilizam no enunciado, e não apenas no modo como podem emoldurar ou circunstanciar o processo. Assim, as relações estabelecidas contribuem para a construção de significados ideacionais no plano discursivo e não apenas na sentença. Em (18), por exemplo, identificamos o uso de "depois", pelo escrevente do gênero tese, para sequenciar um evento no interior do próprio texto. É comum também que essas conjunções funcionem como sequenciadores discursivos, com disposição fórica, como verificamos em (19):

18) [...] temos, portanto, dois conjuntos: um que diz respeito às anotações de campo e aos textos produzidos durante e depois da disciplina PLPT II; e outro que reúne as discussões (depoimentos) do grupo focal. [...] (suc-174-TES)

19) [...] que tem ampliado o leque de interesses e desafios da área no contexto do ensino da produção escrita. Depois, discorremos sobre o contexto e os participantes da pesquisa, fornecendo dados pormenorizados sobre o tipo [...] (suc-102-TES)

Uso diferenciado pode ser identificado na amostra (20), em que o emprego de "antes" não é sequenciador e nem estabelece relação fórica. $\mathrm{Na}$ ocorrência em questão, a oração e seu efeito são expressos por uma realização que chama a atenção do leitor para a ideia que o escrevente pretende sustentar. Nesse caso, o efeito de sentido não se deve ao 
valor conjuntivo da realização léxico-gramatical, tendo em conta que na amostra que segue "antes de tudo" se caracteriza não propriamente como conjunção, mas como um marcador enfático:

20) [...] resultado das investigações, pois, como argumenta Chibeni O sistema de (2012, p. 01): O que caracteriza um texto acadêmico é, antes de conjunção $\underline{\text { tudo, }}$ o seu objeto: ele veicula o fruto de alguma investigação científica, filosófica ou artística. (suc-208-DIS)

em textos acadêmicos: osmecanismos de

No que concerne ao significado de simultaneidade, analisamos sequenciamento duas conjunções: "enquanto isso", com recorrência apenas no gênero e de explicação TCC; e "ao mesmo tempo", presente em todos os textos do corpus, com maior frequência na tese. As amostras da conjunção "enquanto isso" indicam que o escrevente do texto ampliou o sentido temporal que a conjunção abriga, para um valor mais espacial ou referencial, conforme atesta a amostra (21):

21) [...] a proposta de atividade, o que em nosso ponto de vista é bem sugestivo para a prática do professor em sala de aula. Enquanto isso, na última janela chamada de "línea de tiempo" verificamos a imagem abaixo [...] (sim-326-TCC)

Diferentemente dessa conjunção, os sentidos elaborados por "ao mesmo tempo" ocorrem nos quatro textos estudados. Esse tipo de relação se alcança por meio da disposição de um ação/evento que ocorre em concomitância com aquele evento ou processo apresentado na sentença ou período anterior. Esse é o comportamento menos marcado das relações semânticas de simultaneidade nas amostras presentes no corpus em pauta. Se levarmos em conta que dissertação e tese são exemplares produzidos por um pesquisador mais experiente na produção escrita acadêmica, é possível inferir, então, que a composição desse tipo de relação de significado decorre de um pronto estabelecimento de referências mais complexas, que se realizam de maneira não exclusiva.

Merece registro o fato de que esse tipo de conjunção teve a mesma disposição em todas as ocorrências, como ilustra prototipicamente a amostra (22): 
22) [...] considerar que a estrutura lingüística pode adaptar-se ao contexto, ou seja, o contexto pode moldar à gramática e ao mesmo tempo essa gramática pode ser moldada pelos discursos. [...] (sim11-ART)

Chama atenção nos dados a utilização das conjunções "tanto

Orlando VianJr.

Wellington

Vieira Mendes

182

que" e "desde que", com significado de causa e de condição, respectivamente, apenas na tese. Esse dado foi indicado no início, mas, a título de ilustração, dispomos a única ocorrência no texto referido:

23) É inegável que a experiência sinaliza pistas de como ensinar e de como aprender uma língua, tanto que, às vezes, o professor é influenciado a ensinar como aprendeu e, de modo semelhante, o aluno [...] (cau-761-TES)

Uma observação importante acerca desse excerto é o fato de a causa para justificar a defesa da experiência docente como condição "inegável" aparecer modalizada por duas circunstâncias de modo e comparação. Isso pode ser considerada uma demonstração de como o discurso acadêmico é circunspeto, inclusive quando aponta causas para fenômenos já convencionados no senso comum, cujas explicações são absolutamente aceitáveis. Tanto assim o é, que, neste parágrafo, por exemplo, também fazemos uso desse recurso de modalização - obedecendo a uma dinâmica de escrita que tem nessa condição pragmática a razão de ser.

O mesmo se pode dizer das realizações de condição: o produtor textual da tese (nas quatro amostras identificadas no corpus), ao estabelecer combinação de certas atividades, as quais atribui um valor de condicional para o acontecimento do evento subsequente, faz isso como expressão de possibilidade ou impossibilidade (24), de necessidade ou de contingência.

24) Isso, porém, não impede, segundo Candido (1985), que um crítico faça a opção por uma desses elementos desde que o utilize como integrante da estrutura da obra. (con-2841-TES)

As relações lógico-semânticas de consequência, apontadas por Martin e Rose (2007 [2003]), com valores de meio e finalidade, tiveram maior número de amostras no material analisado. Como expressam significados circunstanciados e representam, de certa forma, a maneira 
como algumas aduções são materializadas no discurso, sua recorrência é maior em relação àquelas que expressam causa/condição. No corpus, foram identificadas conjunções iniciando o período (25) ou relacionando eventos (26):

25) Começaremos pelo blog El blog para Aprender Español, representado na imagem abaixo. Por meio da imagem verificamos que o blog possui um título (frame 1) que está de acordo com a descrição do blog (mei-284-TCC)

O sistema de conjunção em textos acadêmicos: osmecanismosde sequenciamento

26) [...] estabelecer relações com pesquisas anteriores; inserir sua pesquisa num contexto mais amplo, por meio da citação de várias pesquisas entre si e seu trabalho; apontar falhas em sua própria pesquie de explicação sa [...] (mei-984-TES)

Por fim, as realizações com sentido de finalidade, em número de dez amostras, foram registradas apenas no TCC e na tese. Seu uso responde basicamente à necessidade de indicar procedimentos, quando os autores abordam aspectos da natureza metodológica de seus trabalhos, ou quando enunciam os objetivos que pretendem atender com o texto. Ou seja, indicam as atividades que se farão necessárias para a consecução daquela apontada como propósito (27):

27) [...] para tal processo sejam utilizados para melhorar o nível de desempenho e aprendizagem dos discentes, a fim de construir boas condições de relações sociais e de interação entre os sujeitos envolvidos neste processo. (fin-196-TCC)

Das análises empreendidas até aqui, foi possível compreender que as características léxico-gramaticais realizadas nos textos contribuem para o entendimento do modo como os significados são construídos no estrato semântico-discursivo, sendo as escolhas operadas nesses estratos (léxico-gramatical e semântico-discursivo) demandam dos diversos contextos de cultura e de situações em que se inscrevem os agentes interactantes da linguagem.

As relações lógico-semânticas - enquanto realização da metafunção ideacional - invocam sentidos que se materializam no discurso e significam na interação, nas situações reais e formadoras de nossos 
repertórios de padrões textuais. No caso específico dos gêneros acadêmicos, as discussões propostas neste artigo ensejam favorecer as práticas de letramento acadêmico, bem como contribuir para a reflexão da escrita acadêmica como prática social.

\section{Considerações finais}

Nosso objetivo neste capítulo foi abordar o sistema discursivo de con-

Orlando VianJr. Junção, um dos seis sistemas que compreendem os sistemas discursivos propostos por Martin e Rose (2007 [2003]) para a análise o discurso pela Wellington perspectiva da LSF, focando as ocorrências de relações lógico-semântiVieira Mendes cas de adição, comparação, tempo e consequência.

Halliday (1994, p. xvi) destaca o fato de que a análise do discurso deve basear-se na gramática, isto é, não deve prescindir das realizações no estrato léxico-gramatical, ou seja, as escolhas realizadas pelos produtores textuais no estrato grafofonológico determinam escolhas no estrato léxico-gramatical que, por sua vez, determinam escolhas no estrato semântico-discursivo. Estas, por sua vez, ocorrem em um contexto de situação específico, determinadas pelas variáveis de registro (campo, relações e modo) e são, por seu turno, determinadas pela seleção do gênero discursivo posto em circulação naquela interação específica. Assim, a análise de discurso por essa perspectiva, por essa razão, deve partir de uma concepção estratificada e metafuncional.

A análise aqui empreendida revelou que as conjunções, no corpus sob análise, concentram-se mais entre adição e comparação nos textos do artigo e do TCC, sugerindo que esses textos apresentam uma maior recorrência aos textos-fonte, com menor (re)análise do conteúdo apresentado nos mesmos textos. Essas relações de adição e de comparação se prestam ao papel de acrescentar sequência(s) a um primeiro segmento, podendo estabelecer sentidos de correlações, contraste ou adversidade, ou de alternância - o que denota uma estratégia possivelmente mais simples e, consequentemente, mais recorrente na produção acadêmica de alunos de graduação, aspecto que pode ser investigado em estudos futuros para comprovação ou refutação de tais hipóteses.

Foi possível perceber, a exemplo da proposição teórica, que as relações lógicas construídas no texto situam e constroem o discurso porque configuram relações/atividades dentro do próprio texto e para além dele, havendo muitas vezes, inclusive, certa gradação argumenta- 
tiva construída a partir das escolhas operadas pelas conjunções. Estas, frequentemente, são também empregadas como recurso para construção de metáfrase, transposição e/ou ampliação.

As amostras analisadas no corpus, portanto, reforçam as possibilidades de que os efeitos desejados por seus autores podem concorrer nas diferentes construções léxico-gramaticais, esses valores semânticos específicos das conjunções aqui tratadas.

Reforçamos o fato de que os demais sistemas discursivos ocorrem simultaneamente ao sistema de conjunção, desvelando os outros tipos de significados interpessoais, ideacionais e textuais que não foram aqui abordados. A seleção por um sistema em específico deve-se apenas à opção metodológica e ao recorte dos dados escolhido pelos pesquisadores, em função das ocorrências verificadas em análise preliminar.

O sistema de

conjunção

em textos

acadêmicos:

osmecanismos de sequenciamento e de explicação teoria e sua aplicação à língua portuguesa e, por essa razão, novos estudos devem ser desenvolvidos para ampliação e compreensão dos fenômenos conjuntivos em nosso idioma, pois é necessário um direcionamento específico para questões tipológicas que apresentam diferenças para o sistema concebido para a língua inglesa e, por certo, adaptações teóricas e terminológicas deverão ser empreendidas a partir do que expusemos aqui.

Mesmo com tais restrições a se considerar, o que se depreende dessa abordagem, no entanto, é que a análise traz à tona aspectos relacionados ao contexto em que os textos foram produzidos e que estão intrinsecamente relacionados aos produtores textuais e suas motivações para tais escolhas em detrimento de outras que poderiam ter sido feitas, mas que revelam a premissa de Halliday (2002 [1982]) apontada na epígrafe deste capítulo: textos são produtos de processos de construção de sentidos.

\section{Referências}

CASTILHO, A. T. Nova gramática do português brasileiro. São Paulo: Editora Contexto, 2010.

HALLIDAY, M. A. K. Language as social semiotic: the social interpretation of language and meaning. London: Edward Arnold, 1978.

. An introduction to functional grammar. London: Edward Arnold, 1985. 
Orlando VianJr.

An introduction to functional grammar. $2^{\text {nd }}$ edition. Londres: Edward Arnold, 1994.

. Text semantics and clause grammar: how is a text like a clause? In: WEBSTER, J.J. (Ed.). On grammar - Volume 1 in the Collected words of M.A.K. Halliday. Londres e Nova York: Continuum, 2002, pp. 219-260.

HALLIDAY, M. A. K.; HASAN, R. Cohesion in English. London and New Wellington York: Longman, 1976.

Vieira Mendes

HALLIDAY, M. A. K; MATTHIESSEN, C. M. I. M. An introduction to 186 functional grammar. Third Edition. London: Hodder Education, 2004.

MARTIN, J. R. English text - System and structure. Philadelphia/ Amsterdam: John Benjamins Publishing Company, 1992.

. Discourse studies. In: HALLIDAY, M. A. K; WEBSTER, J. J. Continuum companion to Systemic Functional Linguistics, 2009, pp. 154-165.

MARTIN, J. R.; ROSE, D. Working with discourse - Meaning beyond the clause. London and New York: Continuum, 2007 [2003].

MENDES, W. V. As circunstâncias e a construção de sentidos no blog. Dissertação de mestrado em Letras. Pau dos Ferros: Universidade Estadual do Rio Grande do Norte, 2010.

NEVES, M. H. M. Gramática de usos do português. 2a ed. São Paulo: Editora da Unesp, 2011.

SCOTT, M. WordSmith Tools. Oxford: Oxford Univesity Press, 2012. 